\title{
Modeling the effect of traffic jam on driver's level of fatigue
}

\author{
Nizami Gyulyev ${ }^{1}$, Oleksii Lobashov ${ }^{1}$, Oleksii Prasolenko ${ }^{1}$, and Igor Bugayov ${ }^{1}$ \\ ${ }^{1}$ O. M. Beketov National University of Urban Economy in Kharkiv, Ukraine
}

\begin{abstract}
This study focuses on establishing the dynamics of changes in the level of fatigue of an average driver in a traffic jam, which affects road safety. Linear and nonlinear models of the effect of traffic jam on the level of fatigue of an average driver have been developed, which allow assessing their condition depending on the driver's age and the duration of the jam. Using a nonlinear regression model, the graphs of changes in the level of fatigue of an average driver of 25 and 65 years are plotted. The analysis of these graphs allowed us to establish the patterns of influence of road parameters on the functional state of the driver. The level of fatigue of the driver, which is determined by the change in his functional state, increases during his stay in the traffic jam. Therefore, the duration of the jam and the initial level of fatigue when entering the jam influence most the final level of fatigue of the driver. The driver's age affects the level of fatigue to a lesser extent, but still significantly.
\end{abstract}

\section{Introduction}

The increase in the level of motorization leads to saturation and oversupply of the urban transport system with traffic flows. This leads to traffic which excesses the capacity of the road network and the emergence of queues of vehicles and traffic jams, especially at the road intersections in the morning and evening peak periods. Basically this interaction is random. The traffic flow may be also considered as a complex system that needs to be constantly managed. The driver is the active element of this system, and his state determines the efficiency of the entire transport system of the city to a large extent [1-3].

The traffic flow consists of cars that have different dynamic characteristics and are driven by drivers with different psycho-physiological features [4]. Drivers manage vehicles at their discretion in accordance with the chosen goals and objectives. The presence of the human factor in the transport stream, as the main element of the system "human technology - environment", and its manifestations, which are difficult to predict, determine the likelihood of the flow [5]. Traffic jams at intersections during peak periods significantly increase travel time and reduce the speed of traffic. Being in traffic jams adversely affects the psychophysiological state of the driver, causing deterioration of his functional state and a number of mental disorders [6-9]. Drivers of non-route vehicles try to choose such a route that would ensure minimum time and comfortable conditions of the trip $[10,11]$. 
Negative emotions caused by excessive restriction of the driver's freedom of activity and the unsatisfactory state of the traffic organization lead to a violation of the driver's mode of work, his emotional stress and, ultimately, to the development of fatigue. Excessive level of fatigue leads to an increase in the driver's reaction time and an increase in the probability of a traffic accident $[2,3,12-15]$. The purpose of the study is to simulate the effect of traffic jam on the functional state of the driver. To achieve it, the following tasks were set: selection and justification of the method for assessing the level of fatigue and developing a model for changing the level of fatigue of the average driver.

\section{Literature review}

Road safety is determined by the reliability of the "driver - car - road - environment" system and above all the reliability of the most important element of this system - the driver. The authors of the works $[1,13]$ stressed the need to take into account the role of the human factor in the traffic organization. It was noted that the design and operation of the transport system must take into account the capabilities of a person in the performance of their duties. There are a number of factors that can lead to accidents, as well as measures to improve the road safety. One of the most significant factors that have a negative impact on the functional state of the driver is the road jam $[16,17]$. Such qualities of a driver as reaction time, work experience, temperament were considered by the authors of works [2, $19]$ in their studies. The growth of emotional tension leads to a temporary breakdown of some mental functions of the driver, increasing the time of his reaction [17-19]. However, in these works the issues of the influence of the initial state of drivers on the change in their final functional state during their stay in traffic jams and the influence of the driver's age on the dynamics of changes in his state in a traffic jam are not fully considered.

\section{Materials and methods of studying the impact of traffic jam on the driver's level of fatigue}

\subsection{The categories of drivers and equipment used in the experiments}

The conducted experimental research involved drivers of all ages and categories. To develop a regression model of the average driver, the drivers of all types of the nervous system were examined.

Of all the psycho-physiological methods for solving described problem, the most suitable method for assessing the functional state is usage of electrocardiogram registering. In psychophysiology, an electrocardiogram serves as the main indicator of a person's emotional state during physical and mental stress [13]. The electrocardiogram is fixed by a "Cardiosens" portable electrocardiograph with autonomous power supply.

In the presented study, the general population consists of all the drivers of the city, who use transport means during the trip. The correspondence of the sampling structures and the general population was established according to the type of the nervous system. For the quantitative compilation of the sample and the determination of its conformity with the general population, the research results given in the works $[20,21]$ were used. The work [21] presents the results of studies on the type of the nervous system with percentage share of respondents: sanguine $-27.2 \%$; choleric $-30.3 \%$; phlegmatic $-27.2 \%$; melancholic $15.3 \%$. The results close to these are also presented in [20], with the research sample: sanguine persons - 26-30\%; choleric - 28-31\%; phlegmatic - 25-27\%; melancholic - 15 $19 \%$. These ratios were taken as the basis for the research.

\subsection{Methodology of conducting experimental research}


Experimental studies consist in fixing the electrocardiogram of drivers at the entrance to the traffic jam, in the jam and at the exit from it.

The sequence of cardiointervals of an electrocardiogram is coded information about the processes that take place not in the heart itself, but in different parts of the control system: the nerve plexuses; endocrine glands; nerve centers located deep in the brain. The structure of the heart rate can be judged by the state of the regulation mechanisms. This is an integral assessment of body fatigue. The methodology is based on the theory of directly proportional dependence of irregularity of cardiointervals and level of fatigue, which in literary sources is often called an indicator of the activity of regulatory systems of the body. It is calculated in conditional units (according to R. M. Baievskyi) using a special algorithm that takes into account statistical indicators, histogram indicators, and data from spectral analysis of cardiointervals. The level of fatigue allows us to differentiate various degrees of tension in the regulatory systems and evaluate the adaptive capacity of the organism [22]. It is calculated according to an algorithm that takes into account five criteria: the total effect of regulation; the automatism function; the vegetative homeostasis; regulation stability; activity of the subcortical nerve centers. Depending on the level of fatigue, it is determined what state a person is in: up to 3 points is the normal state; from 3 to 6 points is the state of stress; from 6 to 8 points is the state of overstrain [22].

\section{Results of studies on the effect of a traffic jam on the level of driver's fatigue}

The task of developing a regression model of the impact of a traffic jam on the functional state of the driver is creating a tool that will allow making correct, reasonable choice of the object of research and determine a set of factors that affect the behaviour of the object. Drivers of different temperaments act as an object within this research. Factors influencing the outcome of the study should be carefully selected. The following factors were taken into account when compiling the regression model: driver's age, driver's work experience, number of lanes on the road, comfort of the car, duration of stay in the traffic jam, the values of the driver's functional state before the stop.

The developed model has the following form:

$$
L_{f e x}=0.037 \cdot D_{a}+0.135 \cdot T_{j}+0.61 \cdot L_{f e n}
$$

where $L_{f e x}$ is fatigue level of while exiting the traffic jam, c. u.; $D_{a}$ is the driver's age in years; $T_{j}$ is driving duration in the traffic jam, min; $L_{f e n}$ is level of fatigue while entering the traffic jam, c. u.

The results of calculations of the parameters of the model are given in Table 1.

Table 1. Characteristics of model of the change in the functional state of a driver in a traffic jam.

\begin{tabular}{|l|c|c|c|c|c|}
\hline \multicolumn{1}{|c|}{ Factors } & $\begin{array}{c}\text { Marking, } \\
\text { dimension }\end{array}$ & $\begin{array}{c}\text { Measurement } \\
\text { limits }\end{array}$ & Coefficient & $\begin{array}{c}\text { Standard } \\
\text { mistake }\end{array}$ & $\begin{array}{c}\text { Student } \\
\text { criterion }\end{array}$ \\
\hline Driver's age & $D_{a}$, years & $19-67$ & 0.037 & 0.006 & 5.84 \\
\hline Duration of traffic jam & $T_{j, \text { min }}$ & $2-20$ & 0.135 & 0.018 & 7.18 \\
\hline $\begin{array}{l}\text { The level of fatigue at the } \\
\text { entrance to the traffic jam }\end{array}$ & $\begin{array}{c}L_{f e n,} \\
\text { conditional } \\
\text { units }\end{array}$ & $2.2-5.8$ & 0.617 & 0.055 & 11.24 \\
\hline
\end{tabular}

In order to improve the description of the impact of traffic jam on the functional state of the driver, a non-linear model was developed: 


$$
L_{f e x}=0.018 \cdot D_{a}+1.278 \cdot T_{j}^{0,41}+0.291 \cdot L_{f e n},
$$

where $L_{f e x}$ is fatigue level of while exiting the traffic jam, c. u.; $D_{a}$ is the driver's age in years; $T_{j}$ is driving duration in the traffic jam, min; $L_{f e n}$ is level of fatigue while entering the traffic jam, c. u.

The results of the calculation of the parameters of the model are given in Table 2.

Table 2. Characteristics of model of the change in the functional state of a driver in a traffic jam.

\begin{tabular}{|l|c|c|c|c|c|}
\hline \multicolumn{1}{|c|}{ Factors } & $\begin{array}{c}\text { Marking, } \\
\text { dimension }\end{array}$ & $\begin{array}{c}\text { Measuremen } \\
\text { t limits }\end{array}$ & Coefficient & $\begin{array}{c}\text { Standard } \\
\text { mistake }\end{array}$ & $\begin{array}{c}\text { Student } \\
\text { criterion }\end{array}$ \\
\hline Driver's age & $D_{a}$, years & $19-67$ & 0,018 & 0,006 & 2,98 \\
\hline $\begin{array}{l}\text { Duration of traffic jam } \\
\text { raised to 0,41 degree }\end{array}$ & $T_{j, \text { min }}$ & $2-20$ & 1,278 & 0,122 & 10,48 \\
\hline $\begin{array}{l}\text { The level of fatigue at the } \\
\text { entrance to the traffic jam }\end{array}$ & $\begin{array}{c}L_{f e n,} \\
\text { conditional } \\
\text { units }\end{array}$ & $2,2-5,8$ & 0,291 & 0,066 & 4,36 \\
\hline
\end{tabular}

It is clear from Table 2 that in the developed mathematical model only three factors turned out to be significant. Their significance is indicated by the excess of the calculated value of the Student's t-test over the tabular.

The adequacy of the developed mathematical model was estimated using the average approximation error of $19.28 \%$. This error is large and therefore the use of the developed model for calculations is possible only in the first approximation.

The non-linear model has approximately the same error as the linear one, so any of them can be used for calculations. This is explained by the fact that during their stay in traffic jams, the functional status of drivers with different temperaments changes differently.

When analyzing the experimental data, it was found that in some cases the values of the level of fatigue at the exit from the traffic jam turned out to be lower than the values of the level of fatigue at the entrance to the traffic jam. This indicates that for some drivers, mostly phlegmatic ones, the functional state in the traffic jam does not deteriorate. However, in the vast majority of drivers, the functional state deteriorates, which leads to an increase in the likelihood of an accident.

To assess the impact of traffic jam on the level of fatigue of the average driver, graphs were constructed with various combinations of the initial level of fatigue. Corresponding graphs were built for drivers aged 25 and 65 years (Fig. 1 and 2).

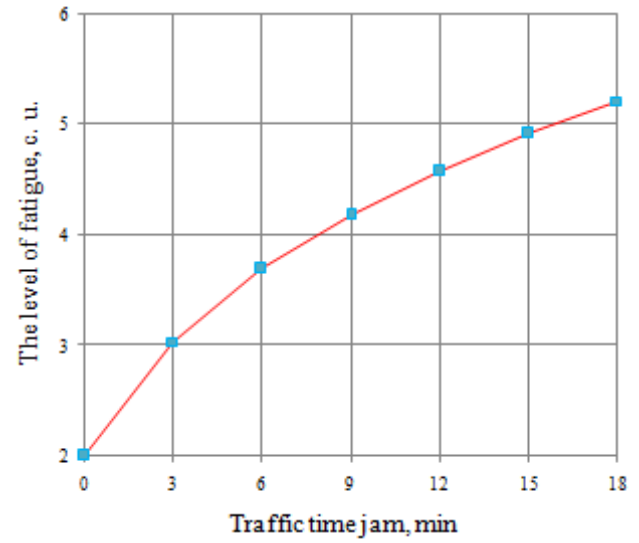

$a$

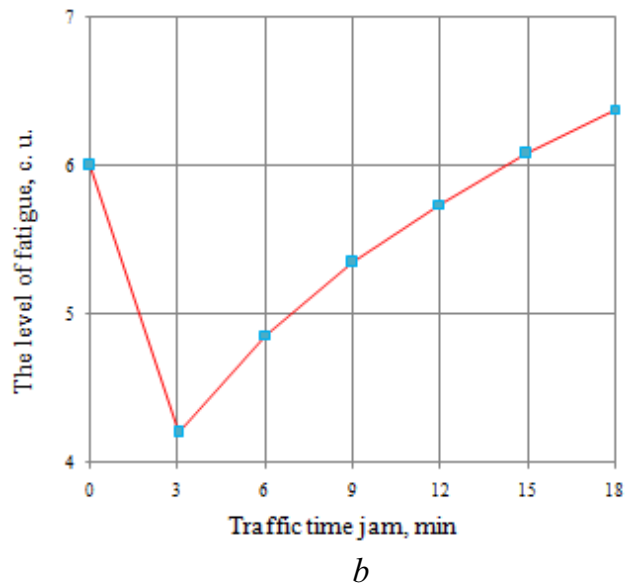

$b$

Fig. 1. Dependence of the change in the level of fatigue of an average driver at the age of 25 in a traffic jam at: $L_{f e n}=2$ c. u. (a), and $L_{f e n}=6$ c. u. (b). 


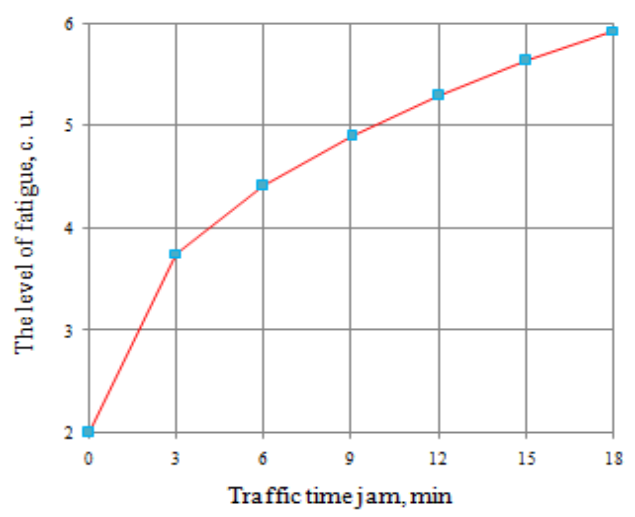

$a$

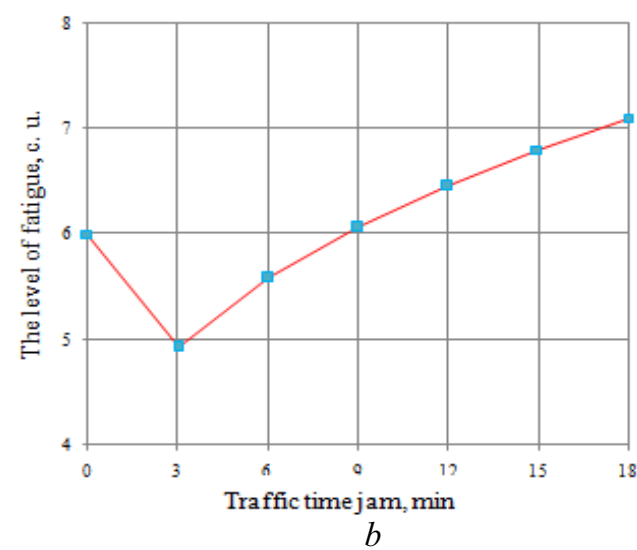

$b$

Fig. 2. Dependence of the change in the level of fatigue of the average driver of 65 years of age in a traffic jam with: $L_{f e n}=2$ c. u. (a) and $L_{f e n}=6$ c. u. (b).

It is clear from Fig.1 that the level of fatigue of the average driver at the end of the traffic jam increases significantly more than five c. u., which reflects the state of the expressed tension of regulatory systems.

If at the entrance to the traffic jam the initial level of fatigue is six conditional units, the functional state of the driver until the third minute of the jam first improves, and then gradually deteriorates (Fig. 1 (b)). In addition, the value of the level of fatigue of the average driver in Fig. 1 (b) exceeds six c. u., indicating a pronounced overstrain of regulatory mechanisms.

Dynamics of change of a functional state of the sixty-five-year-old driver on Fig. 2 is similar to the change in the functional state shown in Fig. 1, however, is more pronounced.

It follows from Fig. 2 (a) that the driver's fatigue level rises throughout the entire traffic jam, reaching six or more c. u. at the end of it. The driver's condition (Fig. 2 (b)) at the beginning of the jam slightly improves. The improvement in the jam is due to the fact that he entered the jam in a stressed state. Further, driver's condition deteriorates significantly.

In addition, the value of the level of fatigue of the average driver exceeds seven c. u., indicating a pronounced overstrain of regulatory mechanisms.

An analysis of Figures 1-2 shows that such a factor as the age of a driver has a different effect on his level of fatigue and, consequently, on the likelihood of a traffic accident.

Young drivers adapt faster to changes in road conditions than older drivers, including the impact of traffic jam. Their state and level of fatigue are more likely to recover from the adverse effects of jam due to their biological age.

\section{Conclusion}

The studies conducted and the regression models compiled testify to the objective and negative impact of the traffic jam on the functional state of the driver. The most significant factors affecting the condition of the driver in a traffic jam are identified. The developed models, adequately reflect the influence of traffic jam on the functional state of the driver, and can be applied for practical use in the first approximation. The value of the initial level of fatigue has a different effect on the functional state of the driver during his stay in a traffic jam. So, if a driver gets into a traffic jam with an initial state $\left(L_{f e n}=5-6\right.$ conditional units), then in the first 3-5 minutes his functional state improves by $10-20 \%$, and then it gets worse. These trends are characteristic for drivers of all ages. The most significant effect of the duration of the jam is observed among drivers of the older age. When analyzing the experimental data, it was found that in some cases the value of the level of 
fatigue at the exit from the traffic jam turned out to be less than the value of the level of fatigue at the entrance to the jam. This suggests that the functional state of some drivers, mostly phlegmatic ones, does not deteriorate in the traffic jam.

Therefore, to clarify the obtained patterns, further research should be carried out in order to simulate the effect of jam on drivers of different temperaments.

\section{References}

1. F. Gavrilov. SistemologIva na transnortI / PId zag. red. Dmitrichenka M. F. - KiYiv : Znannya UkraYini,. - kn. 5 : ErgonomIka, 256 (2008)

2. N. Gyulyev, C. Dolia. American Journal of Social Science Research, 3(5), 17-24 (2017)

3. N. Gyulyev, O. Lobashov, O. Prasolenko, D. Burko. International Journal of Engineering \& Technology, 7(4.3), 308-314 (2018)

4. M. Zhuk, V. Kovalyshyn, Y. Royko, and K. Barvinska. Eastern-European Journal of Eenterprise Technologies, 2 (3), 24-31 (2017)

5. P. Philip, P. Sagaspe, N. Moore, J. Taillard, A. Charles, C. Guilleminault, B. Bioulac,. Accident Analysis \& Prevention, 37(3), 473-478 (2005)

6. I.. C. Davis, Physica A: Statistical Mechanics and its Applications, 391 (4), 1679-1691 (2012)

7. Kalaižić M.. Miloš K.. Muić M. Simulation Model of Traffic Jam at Crossroads, Promet-Traffic \& Transportation, 14( 6), 309-317 (2012)

8. D. A. Hennessy, D. L. Wiesenthal,. Ergonomics, 40 (3), 348-361 (1997)

9. H. S. Snno. Y. G. Sin, S. C. Gang. Journal of Korean Society of Transportation, 23(2), 61-74 (2005)

10. Y. Li. J. Q. Wang, and J. Wu. Journal of Central South University, 24(6), 1494-1502 (2017)

11. D. Ponkratov, I. Ivanov, O. Prasolenko, T. Grigorova, O. Lobashov, and V. Dolya,. International Journal of Automation, Control and Intelligent Systems, 1 (2), $21-26$ (2015)

12. O. Prasolenko, O. Lobashov, A. Galkin, International Journal of Automation, Control and Intelligent Systems, 1(3), 77-84 (2015)

13. A. Maji, N. R. Velaga, \& Y. Urie, International journal of injury control and safety promotion, 25(3), 257-271 (2018)

14. E. Lagarde, J. F. Chastang, A. Gueguen, M. Coeuret-Pellicer, M. Chiron, S. Lafont, (2004). Emotional stress and traffic accidents: the impact of separation and divorce. Epidemiology, 15, 762-766.

15. J. W. Muttart. Evaluation of the influence of several variables unon driver nercention resnonse times. York. Fngland. In Proceedings of the 5th International Conference of the Institute of Traffic Accident Investigators, 116-129 (2001)

16. N. Gvulyev, Vestnik Natsionalnogo tehnicheskogo universiteta «HPI», 10, 140-144 (2011)

17. N. Gyulyev, Lyudskiy faktor I dorozhnI zatori : monograflya. HarkIv: HNUMG Im. O. M. Beketova, 252 (2016)

18. I. A fanasieva. A Galkin. Assessing the information flows and established their effects on the results of driver's activity. Archives of Transport, 45(1), 7-23 (2018)

19. N. Gyulyev, V. Dolya. Vestnik Natsionalnogo tehnicheskogo universiteta «HPI». 26, 47-50 (2012)

20. K. Stojmenova, J. Sodnik, Detection-Response Task - Uses and Limitations. Sensors, 18(2), 594 (2018)

21. A. G. Koveleva, Psihologiya: ucheb. posobie. Moskva, Prosveschenie, 451 (1966)

22. R. M. Bayevsky, O. I. Kirillov, S. Z. Kletskin, Matematicheskiy analiz izmeneniy serdechnogo ritma pri stresse. Moskva, Nauka», 177 (1984) 